\title{
A morte na poética de Manuel Bandeira
}

\author{
Ana Augusta Wanderley Rodrigues de Miranda \\ Universidade Federal do Espírito Santo
}

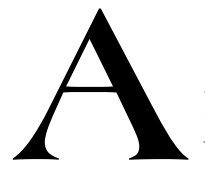

decepção diante da vida é inaugural na poética de Manuel Bandeira. Conta-nos o próprio poeta a história do desenvolvimento de sua técnica literária. No interstício de treze anos (1904 - 1917), que se inicia com seu acometimento pela tuberculose e vai até a publicação de seu primeiro livro de versos, A cinza das horas, a formação da técnica coincide com o reconhecimento das "limitações" trazidas pela doença. ${ }^{1}$ O poeta "ensimesmado" ainda não parece ter descoberto toda a potência lírica da dor como ocorre nos livros posteriores. Em todo caso, anuncia sua estética de forma marcante: "(...) - Eu faço versos como quem morre" ("Desencanto"). O livro é todo escrito com o principal intuito de driblar o sentimento de inutilidade provocado pela doença. Trata-se de um livro taciturno onde encontramos, paradoxalmente, já que é o primeiro, um Manuel Bandeira envelhecido.

O poema "Momento num café", de 1931, incluído em A estrela da manhã, nos traz também a idéia de ressentimento com a vida, mas num tratamento bastante diferente, pois comporta um questionamento universal sobre a existência.

Quando o enterro passou

Os homens que se achavam no café

Tiraram o chapéu maquinalmente

Estavam todos voltados para a vida

Absortos na vida

Confiantes na vida.

Um no entanto se descobriu num gesto largo e demorado

Olhando o esquife longamente

${ }^{1}$ BANDEIRA, 1984. p. 29. 
Este sabia que a vida é uma agitação feroz e sem finalidade Que a vida é traição

E saudava a matéria que passava

Liberta para sempre da alma extinta.

A primeira coisa a nos chamar a atenção neste poema é sua clara divisão em duas partes. A primeira parte parece apontar uma total displicência em relação à morte. Os versos mais curtos permitiriam uma passagem rápida à segunda parte, não fosse o fato de que a repetição da palavra "vida" exige e detém o olhar do leitor. Nossa primeira interrogação do poema diz respeito a essa repetição. A reiteração insistente da vida antepõe uma tela entre o leitor e a morte que passa; a distração dos homens indica que não se lhe deve prestar atenção. A repetição parece ter a função de sustentáculo para nos manter, como aos homens, absortos, confiantes.

Ao tratar da repetição em Freud, Lacan recorre à Física de Aristóteles, onde encontra o termo grego Autômaton, traduzido, segundo ele, erroneamente, por "acaso". Para Lacan, este termo indica o retorno incessante dos signos a que tem que se submeter o sujeito, pelo fato de que participa de um mundo de linguagem. Essa repetição não é mera reprodução, demanda algo novo e traduz o próprio movimento da vida. Toda a elaboração lacaniana do tema tem o intuito de nos conduzir ao Real que é o elemento novo. Em meio à repetição a que o sujeito é conduzido pela linguagem, Lacan se pergunta: onde está o Real? Afirma que todo sujeito tem com ele um encontro marcado, ao qual somos chamados, mas de que o Real sempre escapole porque não se pode abafálo com a rede simbólica. Um segundo termo é retirado de Aristóteles para definir esse encontro: Tiquê, cuja tradução por "fortuna" também desagrada Lacan, vige por trás de Autômaton. É o que nos faz despertar do sonho, aqui não necessariamente compreendido como o processo onírico, mas o sonho de viver, aquilo que nos permite ficar distraídos como os homens no café. O significante "maquinalmente" do poema remete ao modo automático com que se pode participar da vida diária, como se nada nos pudesse atingir. E se, porventura, algo do Real se apresenta nos despertando do sonho, ainda temos a alternativa de acordar, recobrar a consciência para continuar sonhando. Como afirma Lacan, não se pode, entretanto, escapar a esse encontro, por maiores que sejam as forças que nos prendem à vida. Na segunda parte do poema vemos a inocuidade do apego à "agitação feroz" do viver. 
Um dos homens é capturado pela presença da morte. O gesto de tirar o chapéu demoradamente se contrapõe ao modo maquinal dos demais. Mais do que uma percepção momentânea, este homem sabia da falta de finalidade da vida. Este saber não designa, contudo, uma elaboração consciente. A análise de Carpeaux, como indica Rosenbaum, deduz daí uma penetração poética em que a conclusão não é fruto de raciocínio, mas de uma disposição. Tais dados analíticos nos remetem a declarações do próprio Bandeira no Itinerário de Pasárgada, referindose a seus primeiros livros. Afirma que seu esforço de consciência sempre resultou em insatisfação. Seu "estado de graça" surge, ao contrário, em momentos nos quais é afetado por uma espécie de "transe ou alumbramento". Sua condição de poeta se instaura apenas "quando Deus é servido". ${ }^{2}$ Ao tomarmos o presente poema, encontramos que o "transe" é o que melhor aproxima do Real, ao passo que o esforço de apegar-se à vida mantém a ilusão.

Onde está o Real no poema? Na matéria que passava liberta da alma. O que resta é apenas o concreto do corpo e a alma, que se poderia compreender como aquilo que oferece ao humano seu estatuto, é considerada um escolho que se perde com alívio.

E saudava a matéria que passava

Liberta para sempre da alma extinta.

\section{A perda do outro: presença da ausência}

A Mário de Andrade ausente

Anunciaram que você morreu.

Meus olhos, meus ouvidos testemunham:

A alma profunda não

Por isso não sinto agora a sua falta.

Sei bem que ela virá

(Pela força persuasiva do tempo)

Virá súbito um dia,

${ }^{2}$ BANDEIRA, 1984. p. 30. 
Inadvertida para os demais.

Por exemplo assim:

À mesa conversarão de uma coisa e outra.

Uma palavra lançada à toa

Baterá na franja dos lutos de sangue,

Alguém perguntará em que estou pensando,

Sorrirei sem dizer que em você

Profundamente.

Mas agora não sinto a sua falta.

(É sempre assim quando o ausente

Partiu sem se despedir:

Você não se despediu.)

Você não morreu: ausentou-se.

Direi: Faz tempo que ele não escreve.

Irei a São Paulo: você não virá ao meu hotel.

Imaginarei: Está na chacrinha de São Roque.

Saberei que não: você ausentou-se. Para outra vida?

A vida é uma só. A sua continua

Na vida que você viveu.

Por isso não sinto agora a sua falta.

Como na primeira estrofe de "Momento num café", encontramos, neste poema, uma morte que, apesar de percebida, é recusada. A análise de Yudith Rosenbaum indica que o caráter dialógico do poema encobre o monólogo interior em que o poeta tenta suprimir a ausência do amigo por meio da palavra. Já no título se marca a presença da ausência. O destinatário é nomeado como em uma carta, mas sua condição de ausente é assinalada. A autora observa que o poema se constrói com base numa tensão entre pares opositivos que é superada na harmonia da linguagem, ainda que as pulsações da tensão continuem presentes. Interessa-nos destacar a oposição entre a aceitação e a recusa da ausência em que, a nosso ver, essa última sobressai. Nesse ponto, faz-se necessário entrar no tópico literário do ubi sunt? apropriado por Manuel Bandeira da tradição e transcrito para sua forma muito particular de lidar com a questão da perda através da linguagem.

A fórmula do ubi sunt? remonta aos escritos bíblicos e é a abreviação da questão "Ubi sunt qui ante nos in mundo fuere?" que se traduz por "onde estão aqueles que estavam no mundo antes de nós?" Foi 
especialmente utilizada na Idade Média, momento histórico em que, como nos mostra Huizinga, acompanhado depois por Ariès e outros, a presença da morte se notava de forma obsessiva na literatura e nas artes em geral. Manuel Bandeira apropria-se desse lugar comum da tradição e lhe oferece inúmeras vertentes bem adaptadas à tradição moderna a que pertence. O ubi sunt? pode aparecer associado ao carpe diem, que alarga a meditação em torno da questão da existência, levando à constatação de que se deve aproveitar a vida enquanto é tempo, já que a finitude é fato incontestável. Retornando a "Momento num café", percebemos que a questão se apresenta, ainda que oculta pela afirmação de uma certeza. O homem parece meditar sobre o destino dos que se vão, mas propõe de pronto sua conclusão:

Olhando o esquife longamente

Este sabia que a vida é uma agitação feroz e sem finalidade

Entretanto, o carpe diem não faz aqui seu aparecimento, pois, como já indicamos, o tom do poema leva a pensar no ressentimento com a vida. Davi Arrigucci ressalta a função, bem consoante com a poética de Bandeira, que se pode extrair do ubi sunt?, e que diz respeito a tornar a morte um fato aceitável. O ubi sunt?, nos diz Arrigucci, seria mais um dos meios que o homem encontrou para lidar com a morte, não só para ressaltar o aspecto devastador do tempo, mas principalmente para instaurar uma meditação que torne admissível a idéia de morrer. Mais uma vez estamos diante do aprender a morrer.

No poema "A Mário de Andrade ausente", a aprendizagem que se faz necessária é em relação à perda do outro. Mas o aprendiz se esquiva, recusando os dados que lhe vêm da realidade. Sua meditação solitária, embora dirigida ao outro (não só a Mário de Andrade, mas também ao leitor), produz uma circularidade, onde o ponto de partida da meditação retorna, não o fazendo avançar a uma outra conclusão. Ele permanece na afirmação que Rosenbaum aponta como denegatória. Reitera por três vezes que não sente, no momento, a falta do amigo.

No futuro, entretanto, o sujeito sabe que a falta virá. Novamente o saber não deve ser considerado como fruto da racionalização, como apontamos em relação ao poema anterior. A certeza da falta, embora prevista, surgirá de modo súbito e violento, conduzida pela palavra. 
Virá súbito um dia,

[...]

Uma palavra lançada à toa

Baterá nas franjas dos lutos de sangue,

A palavra que bate nos lutos do sujeito nos remete ao encontro com o Real prometido por Lacan. O Real está sempre em seu lugar de onde espreita o sujeito e seu aparecimento se deve ao Simbólico, à palavra. A capacidade de fazer existir o que está ausente é inerente ao Simbólico. Através da linguagem, o objeto ausente pode se manifestar pela representação. Mário de Andrade sobrevive concretamente no Simbólico e Manuel Bandeira parece apontar, nessa saída que consola, uma proximidade maior entre vida e morte. Seguindo ainda as formulações de Lacan, encontramos que tudo que existe, existe sobre um fundo de ausência; o fato mesmo de existir implica a inexistência.

Existir e não existir são, portanto, movimentos que pertencem ao Simbólico; essa dialética não faz sentido no Real, pois ele, como já afirmamos, está sempre em seu lugar. A morte está sempre em seu lugar. É a única certeza do vivente. Entretanto, há várias formas de fazer sua transposição para o Simbólico, como as que Manuel Bandeira nos oferece. A questão é que essa transposição nunca pode se dar completamente, pois o Real escapole. Assim, a recusa veemente da morte que encontramos na análise semântica do poema força a admitir sua presença na estruturação simbólica e, mais do que isso, uma presença que permanecerá em parte desconhecida, para além de todo esforço de assimilação ou de recusa.

O drama implacável da presença da morte, portando sua vertente Real, surge em "Boi morto".

$* * *$

\section{O inassimilável}

No poema "Boi morto" a familiaridade almejada entre o poeta e a morte se rompe. O tema, mais uma vez trazido à cena poética, evidencia agora todo o desconhecimento e estranheza que o sujeito experimenta diante dele. Trata-se de uma inundação do inassimilável.

Como em turvas águas de enchente,

Me sinto a meio submergido

Entre destroços do presente 
Dividido, subdividido,

Onde rola, enorme, o boi morto,

Boi morto, boi morto, boi morto.

Árvores da paisagem calma,

Convosco - altas, tão marginais! -

Fica a alma, a atônita alma,

Atônita para jamais.

Que o corpo, esse vai com o boi morto,

Boi morto, boi morto, boi morto.

Boi morto, boi descomedido,

Boi espantosamente, boi

Morto, sem forma ou sentido

Ou significado. O que foi

Ninguém sabe. Agora é boi morto,

Boi morto, boi morto, boi morto!

A primeira estrofe do poema mostra a posição de conflito e divisão em que se acha o eu lírico. Identifica-se ao animal sem vida, situando-se no mesmo espaço que ele, as águas turvas do rio. É a partir dessa experiência de desorganização subjetiva (entre destroços e dividido), que a morte será encarada. Logo em seguida à apresentação da situação do Eu, o boi morto acede ao primeiro plano, no qual permanecerá até o final. A segunda estrofe marca a separação da alma e do corpo; a alma permanece à margem enquanto o corpo segue o curso juntamente com o boi. $\mathrm{O}$ abandono da alma na margem, enquanto o poema continua a fluir carregando consigo a matéria, indica a importância menor que o poeta concede à transcendência. Na estrofe final, o boi, que é a imagem da própria morte, invade completamente a cena coroando a falência do sentido.

A falta de sentido abandona o sujeito na dimensão do espanto. Freud designa esse tipo de experiência a partir da noção de "unheimlich". Antônimo de "heimilich", familiar, pertencente ao lar, o termo, em sua ambigüidade, é apontado, depois de uma acurada análise etimológica, não apenas como o contrário do que é conhecido, mas como um caminho que leva do conhecido ao estranho. "Unheimlich" é aquilo que, de tão familiar, precisou ser ocultado da visão de forasteiros e que, de tão bem escondido, escapou também aos de casa. Mas a sensação de estranheza só se produz se "unheimlich" vier à tona. Ele é o que deveria ter permanecido escondido, mas veio à luz. 
Interessa-nos ressaltar, na teoria freudiana, o fato de que toda a análise do estranho se dá na vertente do significante. "O estranho" é um dos muitos artigos em que Freud parte do texto literário, no caso, $O$ homem de areia, de Hoffmann. Além disso, tudo que extrai desse texto depende da análise etimológica da palavra, ressaltando a importância primordial que o pai da psicanálise atribui ao significante. Não nos é preciso supor que o estranho remeta a uma imagem ou representação oculta; não há nada a ser desvendado por trás dessa sensação. O que afeta o sujeito é justamente o fato de que não há nada. O que o estranho lhe revela é o vazio. O que deveria ter permanecido escondido e veio à luz não é nenhuma essência, mas o buraco nas representações. Lacan dirá que o que não veio à luz no Simbólico reaparecerá no Real. É do encontro com o Real que se trata no estranho. Em sua tentativa de apreender a totalidade da vivência pela linguagem, é justamente a falta de sentido o que o sujeito não suporta. É, aliás, por isso que se escreve, em última instância, se abordamos a escrita psicanaliticamente.

O texto de Freud inaugura a noção amplamente divulgada por Lacan de que o inominável não se furta à visão. É na superfície da linguagem que a ausência se mostra. Em "Boi morto", o movimento que supomos furioso das águas de enchente, não nos traz, porém, a imagem de submersão total. A diferença de níveis, o alto e o baixo, diz respeito às posições do rio e das margens, com suas árvores altas. Dentro do rio, o eu lírico fica "a meio submergido", o que leva a supor que está a meio, à tona. O boi rola, mas não nos é indicado que afunde. É a escrita que o mantém à tona. $\mathrm{O}$ acesso à falta de significado se dá na construção poética.

Da rica análise que Arrigucci faz do poema em questão, retiraremos dois pontos, ambos relacionados à questão da matéria. O autor aproxima o poema da atitude expressionista em função da deformação da realidade que a torna grotesca. O boi, que de saída já se apresentava enorme, passa a descomedido, espantoso. A mescla das esferas da realidade (a íntima e a externa) conduz o crítico também ao surrealismo. Percebe ainda a influência da tradição moderna, principalmente a partir de Baudelaire, na justaposição do abjeto com a angústia do sujeito diante da destruição. O que nos importa destacar é o incomensurável que dá a Arrigucci todas essas possibilidades analíticas. Circunscrito pelo Simbólico, o Real ultrapassa os limites, transborda.

Arrigucci evoca uma lembrança de infância de Manuel Bandeira, narrada pelo poeta em uma crônica. Para o crítico, esse evento, que é 
motivo recorrente da obra recebe na prosa e no poema tratamentos diferenciados. Uma parte da visão que perturba o menino nos parece ser imitada pelo poeta em seu trabalho: a atitude heróica dos caboclos que ataram suas jangadas aos pegões da ponte, com o intuito de resgatar o que a água arrastava. O poeta-jangadeiro recolhe os destroços e os transforma em poesia. A ponte, que atravessa o rio de um lado a outro, constitui uma terceira margem de onde o poeta pode fisgar o Real descomedido e submetê-lo, mesmo que em parte, à escritura. Dessa forma, salva-se do naufrágio. Essa possibilidade é fornecida pela prática da letra.

Tal modalidade de prática da letra nos permite aproximar as escritas de Bandeira e Clarice Lispector. Em que pesem todas as diferenças entre as duas poéticas constata-se, também em Clarice Lispector, um convite à morte como fator instaurador da escrita. A morte como tema não é tão presente em Clarice como em Bandeira, mas a força do indizivel a que pode remeter é patente. Trata-se, na escritora, de uma vontade intransigente de abdicar do Simbólico para dar a ver o Real. Entretanto, seu ensejo só se pode realizar parcialmente e, de forma irremediável, pela via da linguagem.

Uma forma contorna o caos, uma forma dá construção à substância amorfa - a visão de uma carne infinita é a visão dos loucos, mas se eu cortar a carne em pedaços e distribuí-la pelos dias e pelas fomes - então ela não será mais a perdição e a loucura: será de novo a vida humanizada. [...] Devo ficar com a visão toda, mesmo que isso signifique ter uma verdade incompreensível? Ou dou uma forma ao nada, e este será meu modo de integrar em mim a minha própria desintegração?

Um outro ponto a ser tratado a partir da análise de Davi Arrigucci é o materialismo que ele atribui, em consonância com outros críticos, a Manuel Bandeira. Há uma valorização do corpo em detrimento da alma, verificada por Arrigucci na posição estática dessa última, deixada para trás como algo descartável, enquanto o corpo ganha movimento. Isso ocorre tanto em "Boi Morto" quanto em "Momento num café". Gostaríamos de acrescentar que o referido movimento não é uma propriedade dos corpos. Em ambos os casos a matéria inerte é carregada, em um poema, pela correnteza das águas e no outro, pelo cortejo fúnebre. A única possibi-

${ }^{3}$ LISPECTOR, 1998. p. 14. 
lidade de supor o Real em movimento é pela via simbólica. Assim, nos permitiremos associar a opacidade da água de enchente que permite à matéria seu movimento, ao registro do Simbólico que, ao contrário do que pretende a ilusão humana, nos mostra com clareza apenas o inassimilável. Todo o sentido que produzimos a partir da corrente da linguagem é passível de ser transformado em equívoco, mal-entendido, ou positivamente, em múltiplos sentidos, como é o caso na escrita literária.

A letra dá força à criação poética na medida em que, com sua materialidade, faz emergir o Real. O aspecto semântico do texto ganha com a presença da letra justamente por que ela transcende ao sentido. Arrigucci mostra como ficamos, literalmente, de boca aberta, ao lermos o seguinte verso:

Fica a alma, a atônita alma,

Tanto o gesto que marca o corpo do leitor, quanto o som que se produz, revelam a materialidade da letra. Som e gesto não têm, por si sós, sentido, mas ampliam a força deste, já que a boca aberta remete à estupefação da alma. Acrescentamos à observação de Arrigucci o refrão que aparece entre as estrofes do poema e que traz, do mesmo modo, som e gestos que se destacam:

Boi morto, boi morto, boi morto.

Em contrapartida, o som que aqui se produz é fechado e a boca é impedida de se abrir. Mas o sentido de perplexidade pode ser ainda atribuído e o som grave e abafado revela o sentimento lúgubre que é experimentado diante do tema.

O que pretendemos assinalar é que determinados elementos textuais, vistos isoladamente, escapam à simbolização e, por isso, ganham destaque no corpo do texto, pois têm a capacidade de transpor, para a escrita, porções do indizível. Cabe acrescentar ainda que tais elementos são constituintes da escrita, mas que apenas alguns autores são capazes de emprestar-lhes sua maestria. É no tratamento a eles oferecido que verificamos as diferentes potências de escrita. 


\section{Referências Bibliográficas}

ALLOUCH, Jean. Letra a letra: transcrever, traduzir, transliterar. Trad. Dulce Duque Estrada. Rio de Janeiro: Campo Matêmico, 1995.

ARIÈS, Philippe. História da morte no ocidente: da Idade Média aos nossos dias. Trad. Priscila Vianna de Siqueira. Rio de Janeiro: Francisco Alves, 1977.

ARRIGUCCI Jr., Davi. Humildade, paixão e morte: a poesia de Manuel Bandeira. São Paulo: Companhia das letras, 1990.

BANDEIRA, Manuel. Estrela da vida inteira. Rio de Janeiro: Nova fronteira, 1993.

—. Itinerário de Pasárgada. Rio de Janeiro: Nova fronteira, 4. ed., 1984. FREUD, Sigmund. O estranho. In: ___ Edição standard brasileira das obras psicológicas completas. v. 17, p. 271- 318. Rio de Janeiro: Imago, 1974.

LACAN, Jacques. O seminário, Livro 11: os quatro conceitos fundamentais da psicanálise. Trad. M. D. Magno. Rio de Janeiro: Zahar, 1985.

___. Escritos. Trad. Vera Ribeiro. Rio de Janeiro: Jorge Zahar, 1998.

LISPECTOR, Clarice. A paixão segundo G. H. Rio de Janeiro: Rocco, 1998.

NANCY, Jean-Luc; LACOUE-LABARTHE. O título da letra: uma leitura de Lacan. Trad. Sérgio Joaquim de Almeida. São Paulo: Escuta, 1991.

MIRANDA, Ana Augusta W. R. O limite da linguagem: a dimensão do impossível na escrita de Clarice Lispector. 2000. Dissertação (Mestrado) - UFES, Vitória.

ROSENBAUM, Yudith. Manuel Bandeira: uma poesia da ausência. São Paulo: Edusp. Rio de janeiro: Imago, 1993. 


\section{Resumo}

As diferentes nuances da presença da morte na poética de Manuel Bandeira parecem seguir, como indica Arrigucci, uma postura ética ampla que é a familiarização com as perdas de si mesmo e dos outros. Essa aproximação não escapa ao estilo humilde do poeta, já que é, na maioria das vezes, expressa em sua costumeira linguagem simples, de maneira a permitir que o leitor comum usufrua o alívio que o autor tenta buscar face às agruras do destino. Em alguns textos verifica-se que mesmo o absoluto desconforto não é recusado pela poética. Fiel a seu ofício, Manuel Bandeira transpõe para a escrita a vertente da morte que escapa à compreensão.

\section{Résumé}

Les différentes nuances de la présence de la mort dans la poétique de Manuel Bandeira semblent suivre, selon la remarque d'Arrigucci, une vaste attitude éthique qui rend familière les pertes de soi même et des autres. Ce rapprochement n'échappe pas au "style humble" du poète, car il est la plupart du temps exposé dans son langage d'habitude simple, d'une telle manière qui permet au lecteur ordinaire de faire l'expérience du soulagement que l'auteur cherche face aux soufrances presentés par le destin. Dans quelques textes, on peut vérifier que même l'absolu abattement n'est pas refusé chez sa poétique. Fidèle a son travail, Manuel Bandeira déplace pour l'écriture le versant de la mort qui échappe à la compréhension. 